\title{
Neurological outcome from conservative or surgical treatment of cervical spinal cord injured patients
}

\author{
J E Kiwerski \\ Spinal Department of Metropolitan Rehabilitation Centre, Konstancin, Poland.
}

This is an analysis of the results of treatment of 1761 patients with traumatic injury of cervical spinal cord, admitted to hospital within the first hours or days after injury. Analysis of the results of conservative treatment in 798 patients and of surgical treatment in 963 patients has shown that the results are to a large extent dependent on the method of treatment and when specialist treatment was started.

Keywords: cervical spinal cord injury; neurological improvement; conservative treatment; surgical treatment.

\section{Introduction}

Early, proper medical management of patients with spinal cord injury is crucial for the future of such patients. In our opinion it is wrong to assume that either surgical or conservative treatment is the only appropriate way of managing such patients. The decision concerning the kind of treatment should be made deliberately, taking into account factors such as: type of spinal injury, degree of spinal cord injury, general condition of the patient, age of the patient, accompanying injuries, etc. We attempt to choose the treatment which will secure the best possible opportunity to obtain neurological improvement and stable consolidation of the injured spine, and to shorten the period of immobilisation of the patient, while at the same time not significantly increasing the risk of a fatal outcome or causing neurological deterioration.

\section{Clinical material}

In the years $1965-1991,1761$ patients with cervical spinal cord injuries, were admitted and treated in the Spinal Injury Department of our hospital within the first hours or days after injury (up to 2 weeks). Table I gives the level and degree of spinal cord injury.
Table I Level and degree of spinal cord injury

\begin{tabular}{|c|c|c|c|c|c|}
\hline \multicolumn{2}{|c|}{$\begin{array}{l}\text { Degree of spinal } \\
\text { cord injury }\end{array}$} & \multicolumn{3}{|c|}{$\begin{array}{l}\text { Level of spinal injury } \\
\mathrm{C} 1-\mathrm{C} 3 \mathrm{C} 3-\mathrm{C} 5 \mathrm{C} 5-\mathrm{T} 1\end{array}$} & Total \\
\hline Complete & & 11 & 270 & 473 & 754 \\
\hline & B & 16 & 84 & 152 & 252 \\
\hline Incomplete & $\mathrm{C}$ & 32 & 147 & 179 & 358 \\
\hline & $\mathrm{D}$ & 48 & 133 & 216 & 397 \\
\hline Total & & 107 & 634 & 1020 & 1761 \\
\hline
\end{tabular}

B. C, D $=$ Frankel grades $^{3}$

Partial injuries of spinal cord are divided into 3 groups, 1.2 corresponding to grades B, C, D of the Frankel classification. ${ }^{3}$ The largest group are those with complete spinal cord injuries ( $43 \%$ of patients). Our department is one of the few specialist departments in Poland managing spinal cord injuries in the acute period. Therefore patients sent to us are more often those who present with significant management problems.

With regard to the level of spinal injury the least common is the $\mathrm{C} 1-\mathrm{C} 3$ segment (including $\mathrm{C} 3$ body fractures); injuries at $\mathrm{C} 3-\mathrm{C} 5$ come next. The most frequent incidence is at $\mathrm{C} 5-\mathrm{T} 1$, making up $58 \%$ of the patients. 


\section{Methods}

The method of procedure is greatly dependent on the nature of the spinal injury. Compression fractures usually require conservative treatment with immediate skull traction. If the spinal cord injury is found not to be clearly related to the degree of spinal column injury, then contrast radiological examination of the vertebral canal is performed in order to exclude the possibility of a prolapsed intervertebral disc. Such studies are also performed in patients with a spinal cord injury if there is no radiological evidence of changes in plane xrays of the spine. Massive fractures known as 'burst fractures' with bone fragments dislocated into the vertebral canal are treated surgically with early decompression of the spinal cord. Fracture of the anterior part of a vertebra from a flexion mechanism is treated in a similar way as for a compression fracture, by skull traction. Dislocation without a vertebral body fracture is usually treated surgically by stabilising the spine at the site of injury with an autogenous bone graft by a anterior approach. Spinal injury from an extension force is usually treated conservatively, by immobilisation of the spine in an orthopaedic collar.

Regardless of the basic method of treat- ment, nursing and rehabilitation procedures are applied the moment the patient is admitted to hospital. In the early posttraumatic period particular attention is paid to breathing exercises and early elevation of the patient in specially designed beds. ${ }^{4}$

\section{Results}

The results of treatment are set out in Tables IIa and IIb. The neurological state on admission is compared to that obtained after hospitalisation. Neurological improvement was achieved in $51 \%$ of patients on the completion of treatment. In the conservatively treated group neurological improvement occurred in $40 \%$ of patients, and in the surgically treated group in $60 \%$. The mortality rate was $14 \%$, accounted for by the large number of complete spinal cord injuries. Mortality in those with a complete spinal cord injury was $27 \%$, and in those with an incomplete spinal cord injury $4 \%$.

Tables IIIa, IIIb and IV present the results of treatment with regard to the time from the injury to the commencement of treatment in a specialist spinal centre. Tables IIIa and IIIb present the results of conservative and surgical treatment, respectively. The results of treatment were

Table IIa Conservative treatment

\begin{tabular}{|c|c|c|c|c|c|c|c|c|}
\hline \multirow{2}{*}{$\begin{array}{l}\text { Spinal cord damage } \\
\text { on admission }\end{array}$} & \multirow[b]{2}{*}{ Complete } & \multirow[b]{2}{*}{$\mathrm{B}$} & \multicolumn{2}{|c|}{ Discharge } & \multirow[b]{2}{*}{ Normal } & \multirow[b]{2}{*}{ Mortality } & \multirow[b]{2}{*}{ Total } & \multirow[b]{2}{*}{ Improvement } \\
\hline & & & $\mathrm{C}$ & $\mathrm{D}$ & & & & \\
\hline Complete & 214 & 6 & 6 & 3 & - & 132 & 361 & $7 \%$ \\
\hline B & - & 9 & 34 & 42 & 2 & 8 & 95 & $90 \%$ \\
\hline C & - & - & 32 & 102 & 11 & 18 & 163 & $78 \%$ \\
\hline D & - & - & - & 62 & 115 & 2 & 179 & $65 \%$ \\
\hline
\end{tabular}

Table IIb Surgical treatment

\begin{tabular}{|c|c|c|c|c|c|c|c|c|}
\hline \multirow{2}{*}{$\begin{array}{l}\text { Spinal cord damage } \\
\text { on admission }\end{array}$} & \multirow[b]{2}{*}{ Complete } & \multirow[b]{2}{*}{ B } & \multicolumn{2}{|c|}{ Discharge } & \multirow[b]{2}{*}{ Normal } & \multirow[b]{2}{*}{ Mortality } & \multirow[b]{2}{*}{ Total } & \multirow[b]{2}{*}{ Improvement } \\
\hline & & & C & $\mathrm{D}$ & & & & \\
\hline Complete & 256 & 22 & 23 & 17 & - & 75 & 393 & $19 \%$ \\
\hline $\mathrm{B}$ & - & 10 & 41 & 93 & 9 & 4 & 157 & $93 \%$ \\
\hline C & - & - & 9 & 132 & 51 & 3 & 195 & $95 \%$ \\
\hline D & - & - & - & 25 & 192 & 1 & 218 & $88 \%$ \\
\hline
\end{tabular}

$\mathrm{B}, \mathrm{C}, \mathrm{D}=$ Frankel grades $^{3}$ 
Table IIIa Results of conservative treatment

\begin{tabular}{lccccr}
\hline $\begin{array}{l}\text { Injury-admission } \\
\text { time }\end{array}$ & Good & Fair & $\begin{array}{c}\text { Results of trauma } \\
\text { No improvement }\end{array}$ & Deaths & Total \\
\hline Up to 6 hours & 85 & 42 & 72 & 60 & 259 \\
$7-12 \mathrm{~h}$ & 42 & 27 & 67 & 41 & 177 \\
$13-24 \mathrm{~h}$ & 33 & 35 & 68 & 45 & 181 \\
$2-3$ days & 16 & 22 & 39 & 10 & 87 \\
4-7 days & 3 & 12 & 30 & 3 & 48 \\
Over 7 days & - & 4 & 41 & 1 & 46 \\
Total & 179 & 142 & 317 & 160 & 798 \\
\hline
\end{tabular}

Table IIIb Results of surgical treatment

\begin{tabular}{lrrrrr}
\hline $\begin{array}{l}\text { Injury-admission } \\
\text { time }\end{array}$ & Good & Fair & $\begin{array}{c}\text { Results of trauma } \\
\text { No improvement }\end{array}$ & Deaths & Total \\
\hline Up to 6 hours & 156 & 47 & 81 & 25 & 309 \\
$7-12 \mathrm{~h}$ & 94 & 30 & 58 & 21 & 203 \\
$13-24 \mathrm{~h}$ & 73 & 39 & 52 & 23 & 187 \\
$2-3$ days & 42 & 43 & 36 & 9 & 130 \\
$4-7$ days & 14 & 24 & 34 & 3 & 75 \\
Over 7 days & 6 & 12 & 39 & 83 & 963 \\
Total & 385 & 195 & 300 & 83 & 963 \\
\hline
\end{tabular}

evaluated on the basis of the comparison of the patient's neurological state on admission to the state obtained after completion of hospital treatment. The neurological improvement was classified as good or fair. The improvement was regarded as good if the pareses disappeared or neurological improvement was sufficient to advance by at least 2 degrees of the scale, eg from group 1 for incomplete injuries (motor paralysis), to group 3 (pareses of lesser intensity). The result was regarded as fair if the neurological score changed by one degree of the scale. It appears that early admission to a specialist department is relevant for a better result of treatment. Thus, in the conservatively treated group of patients admitted within 6 hours after injury good results were obtained in $33 \%$, whereas in those admitted to hospital 2-3 days after injury such results amounted to $18 \%$. In the group admitted 4-7 days after injury such results were noted in $6 \%$ of cases. Similar results were recorded in the group of patients treated surgically. In the group of patients admitted within 6 hours after injury good results were recorded in $50 \%$ of cases; those admitted on the second or third day after injury obtained such results in $32 \%$; whereas in the group admitted within the second week after injury good results were found in $10 \%$.

\section{Duration of hospitalisation}

Hospitalisation time is highly dependent on the degree of spinal cord injury. This is shown in Table IV. The longest time of hospitalisation is seen in patients admitted with symptoms of complete injury of spinal cord. Their treatment usually takes 4-6 months, but urinary and respiratory complications, decubiti etc frequently lengthen this period to over 10 or even 12 months. The average hospitalisation time in this group of patients was 27 and 17 weeks respectively, when conservative or surgical treatment was used. Patients admitted with a partial injury. group 1 , treated conservatively and surgically were hospitalised for a period of 15 and 11 weeks, respectively. The hospitalisation 


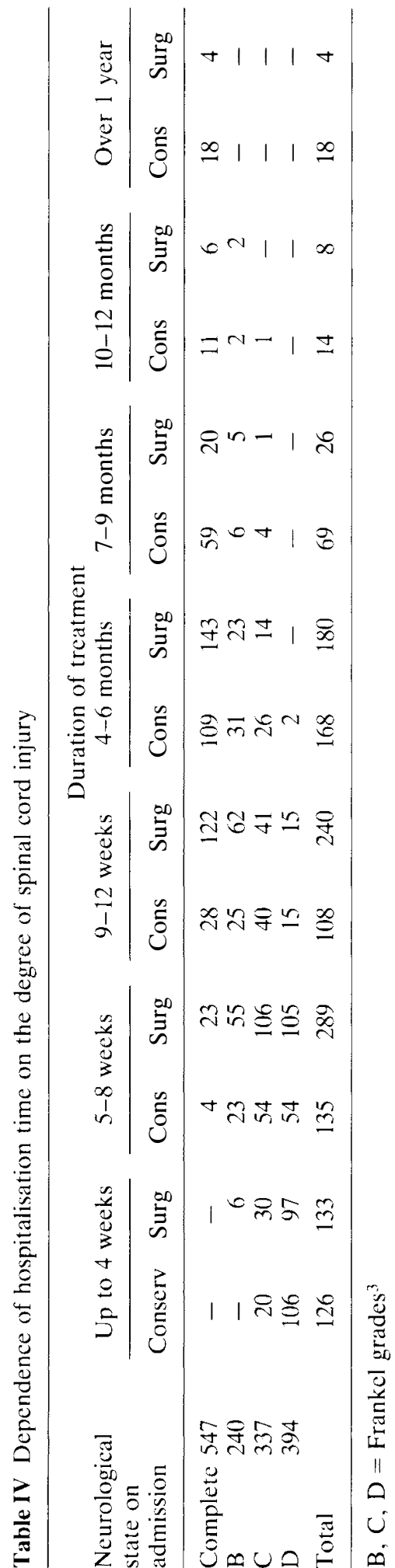

time for surgically treated patients with a partial injury, group 3, was a little longer than those with conservative treatment (4.9 and 4.7 weeks, respectively).

\section{Discussion}

For many years the problem of treating patients with spinal cord injuries has been the subject of passionate discussion and argument among the adherents of conservative and surgical methods of treatment. In the light of our own clinical experience and the presented analysis of clinical material, we are of the opinion that both methods may lead to the desired results of treatment. No direct comparison of the conservatively and surgically treated can be made due to the fact that there was lack of randomisation in assigning the patients to the 2 groups. The practice in our centre to assign patients to surgery or to no surgery is based mainly on the mechanism of the injury. Therefore, the surgical and conservative groups do not have an equal number of patients with all the mechanisms represented. In our opinion, selection of an appropriate form of treatment should be made individually and be based on a reliable analysis of possible neurological improvement and the preclusion of complications. It is evident that the medical staff managing such patients prefer the procedure with which they have more experience. But this preference to apply the favourite method of treatment regardless of other circumstances should be avoided in order to prevent any disadvantage to the patient.

In our country, where there is a shortage of specialist hospitals and spinal departments, there is a tendency to prefer surgical treatment, which in most cases allows a reduction in the time of hospitalisation (Table IV). Wrong qualification for surgery, and surgery performed by a surgeon with insufficient experience in this field, could not only lead to adverse effects and lengthen the time in hospital, but may also affect the general and neurological state of the patient. Therefore, while considering the indications for a particular method of treatment it is vital for us to have in view the main objective, the good of the patient. 


\section{References}

1 Haftek J, Rudnicki S, Kiwerski J (1968) Acute trauma of the cervical segment of the spinal cord. In: M. Weiss, editor. Compensation of the Spinal Cord Function. PZWL, Warszawa: 75-85.

2 Kiwerski J (1989) Spring alloplasty in the treatment of fractures of the thoracic and lumbar spine. Intern Orthop 13: 33-37.

3 Frankel HL, Hancock DO, Hyslop G, Melzak LS, Michaelis GH, Ungar JDS et al (1969) The value of postural reduction in the initial management of closed injuries of the spine with paraplegia and tetraplegia. Paraplegia 7: 179-192.

4 Kiwerski J (in press) Respiratory problems in patients with quadriplegia after a high lesion of the cervical spinal cord. J Intern Rehabil. 